\title{
Social Loafing in the Refugee Crisis: Information about Existing Initiatives Decreases Willingness to Help
}

\author{
Simon Schindler ${ }^{1, *}$ and Gerhard Reese ${ }^{2}$ \\ 1 Department of Psychology, University of Kassel, Holländische Str. 36-38, 34131 Kassel, Germany \\ 2 Department of Psychology, University of Koblenz-Landau, Fortstr. 7, 76829 Landau, Germany; \\ reese@uni-landau.de \\ * Correspondence: schindler@uni-kassel.de; Tel.: +49-561-804-3571
}

Academic Editor: Gregor Wolbring

Received: 21 October 2016; Accepted: 9 May 2017; Published: 11 May 2017

\begin{abstract}
In light of the European refugee situation, we investigate how information about others' support influences individuals' willingness to help. When individuals see information about other people supporting refugees, they may either be influenced by a descriptive norm, and act accordingly. Alternatively, they may perceive that others are already doing the job, and thus engage in social loafing. In an experiment $(N=132)$, we tested these competing predictions. Specifically, participants were exposed to a map of Germany that either indicated many or few helping initiatives across the country. In a control group, no map was shown. Subsequently, participants were asked about their willingness to help. While there was no effect between the two map conditions, results revealed that participants reported lower willingness to help in both map conditions, compared with the control group. Thus, providing information about helping projects results in social loafing, jeopardizing widespread communication strategies to increase solidarity.
\end{abstract}

Keywords: social loafing; descriptive norms; helping behavior; refugees; media

\section{Introduction}

The Syrian and Middle-Eastern refugee crises have generated a significant impact on various Western societies and their governments. Specifically, political decisions within Europe have led to both solidarity-based responses to refugees, but also to the denial of responsibilities and even hostile responses against migrants. For example, in Germany, there was strong solidarity in various regions of the country, with citizens welcoming refugees with presents, food and welcome events [1]. Media outlets reported extensively about such initiatives, and also displayed maps and figures of these on the internet (for example, the popular tagesschau used a visual map to indicate known initiatives [2]). While such maps imply a rather "pro-refugee" attitude (the tagesschau map is titled with "good ideas nationwide"), the effect on its viewers is unexplored. In the current experiment, we sought to understand whether information about existing refugee initiatives increases or decreases individuals' willingness to help refugees. We believe there is reason for both options.

On the one hand, presenting information about the number and distribution of "people helping refugees" might be perceived as a descriptive norm. In contrast to prescriptive norms (which refer to what is commonly approved), descriptive norms refer to what is commonly done, that is, those norms rather reflect an informational social influence based on the perception what most people actually do in a given situation [3,4]. Such "norms" indicate what prototypical members of a certain group are like [5] and affect behavior often unconsciously [6]. For example, informing hotel guests that many previous guests of their particular room re-used their towels resulted in stronger compliance of towel re-use 
than standard, non-normative information $[7,8]$. Such findings suggest that descriptive norms can motivate individuals to act in accordance with them. Thus, it is possible that information about refugee initiatives might be perceived as a descriptive norm, that is, "people are helping refugees". The content of this information might be perceived as a call for action to help refugees, further increasing people's motivation to help refugees.

On the other hand, research on social loafing suggests that the same information about existing refugee initiatives might result in a lower willingness to help refugees. Social loafing [9] (for a metaanalytic review, see [10]) describes the phenomenon that individuals exert less effort to achieving a goal when working collectively rather than on their own. In other words, knowing of others already working towards a certain goal can reduce the motivation to engage towards that goal-for example, because individuals perceive no value in contributing [11]. In the current context, perceiving that many individuals and groups within one's own society are already doing something to help refugees could thus decrease individuals' willingness to help.

To summarize, we test two contrasting predictions. If participants were affected by a descriptive norm of "helping refugees", they would respond in line with this norm, and indicate a stronger willingness to help refugees. Conversely, social loafing research predicts that individuals would show a lower willingness to help, given that others within society already do so. According to previous findings, we further assumed increasing effects of descriptive norms as well as social loafing with increasing group size [10]. When testing this idea, we controlled for dispositional empathy [12]—the concern for others and efforts to understand others' views-which is strongly related to helping behavior [13-15].

\section{Method}

\subsection{Ethics Statement}

Parallel to previous research [16], we state: The study was conducted in full accordance with the Ethical Guidelines of the German Association of Psychologists (DGPs) and the American Psychological Association (APA). The study was evaluated by the authors not to create any harm or distress to the participants. Under this assumption and in line with the above-mentioned rules and customary procedures, a formal ethics approval or a waiver of such an approval were not required. The study exclusively made use of completely anonymous questionnaires; as a result, no identifying information was obtained from participants.

\subsection{Subjects and Design}

We report all measures and manipulations in this study. There was no exclusion of participants. Power was set to 0.80 [17] and sample size to detect a medium effect $(f=0.25)$ was calculated. The power analysis revealed a required sample size of $N=158$ to detect a significant effect (alpha level of 0.05 , two-tailed) given there is a true effect. However, regarding our undirected hypothesis and the unknown effect of the information about the group sizes, the assumed medium effect is highly speculative. The power analysis seems therefore highly error-prone and we thus refrained from a finer grained planning of the sample size. Participants in this online study were 132 German psychology students ( 99 women; $M_{\text {age }}=22.31, S D=5.26$ ). They were randomly assigned to the experimental condition in a $1 \times 3$ (Number of initiatives: low vs. high vs. no information control condition) between-subjects factorial design.

\subsection{Procedure and Measures}

First, we assessed the demographic measures, followed by the measure of individual differences in empathy [12], which consisted of seven items ( $\alpha=0.80$; e.g., "I often have tender, concerned feelings for people less fortunate than $\mathrm{me}^{\prime \prime}$ ) ranging from 1 (not at all true) to 7 (absolutely true). For explorative reasons, we also assessed need to belong [18], trait mindfulness [19] and global identity [20]. Then, 
participants were told that the following study part dealt with the current refugee situation in Germany. They were exposed to a map of Germany that either indicated 25 (low number condition; $n=45$ ) or 170 (high number condition; $n=42$ ) helping initiatives across the country, or to no map (control condition; $n=45$ ). Subsequently, participants indicated their motivation to help in the current refugee situation with three items ( $\alpha=0.89$; "I feel a strong motivation to voluntarily support refugees", "I have a strong need to support refugees", "My willingness to help refugees is very low") ranging from from 1 (not at all true) to 7 (absolutely true). Additionally, we included a binary measure of helping intention ("If you seriously want to support refugees, click yes"). Finally, participants were thanked and fully debriefed.

\section{Results}

First of all, there was a strong positive correlation between helping motivation and intention, $r=0.63, p=0.001$. To analyze the effect of our experimental manipulation on helping motivation (linear regression) and intention (binary logistic regression), we generated three dummy variables: low number (codes: $1=$ low number, $0=$ otherwise), high number (codes: $1=$ high number, $0=$ otherwise), control condition (codes: $1=$ control, $0=$ otherwise). Empathy was included as a further independent variable. There were no differences on empathy across condition, $p=0.363$. Results are summarized in Table 1.

Table 1. Regression coefficients of the main analyses $(n=132)$.

\begin{tabular}{|c|c|c|c|c|c|c|}
\hline Criterion & Predictors & B & $S E B$ & $\beta$ & $p$ & OR \\
\hline $\begin{array}{l}\text { Model } 1 \text { (Linear Regression) } \\
\text { Helping Motivation } \\
\\
\qquad \begin{array}{l}F=12.95 \\
R^{2}=0.23\end{array}\end{array}$ & $\begin{array}{l}\text { Low number } \\
\text { High number } \\
\text { Empathy }\end{array}$ & $\begin{array}{c}-0.57 \\
-0.67 \\
0.77\end{array}$ & $\begin{array}{l}0.27 \\
0.28 \\
0.13\end{array}$ & $\begin{array}{c}-0.19 \\
-0.22 \\
0.46\end{array}$ & $\begin{array}{l}0.038 \\
0.018 \\
<0.001 \\
<0.001\end{array}$ & \\
\hline $\begin{array}{c}\chi^{2}=16.16 \\
\text { Nagelkerke's } R^{2}=0.16\end{array}$ & $\begin{array}{l}\text { Low number } \\
\text { High number } \\
\text { Empathy }\end{array}$ & $\begin{array}{c}-0.93 \\
-0.97 \\
0.86\end{array}$ & $\begin{array}{l}0.49 \\
0.49 \\
0.26\end{array}$ & & $\begin{array}{l}0.056 \\
0.049 \\
0.001 \\
0.001\end{array}$ & $\begin{array}{l}0.40 \\
0.38 \\
2.37\end{array}$ \\
\hline
\end{tabular}

Reference category dummies: control condition; low number (codes: $1=$ low number, $0=$ otherwise), high number (codes: $1=$ high number, $0=$ otherwise).

We first regressed helping motivation on low number, high number, and empathy by using a General Linear Model (Model 1). Results revealed that empathy, low number as well as high number significantly predicted helping motivation. That is, helping motivation was positively linked to higher levels of reported empathy, and was lower in the low number as well as in the high number condition compared to the control condition. These effects remained significant when additionally including need to belong, mindfulness, and global identity as further independent variables. None of these variables significantly predicted helping motivation (need to belong: $B=-0.15, p=0.224$; mindfulness: $B=0.06, p=0.620$; global identity: $B=0.23, p=0.066$ ). Regressing helping motivation on control condition and low number revealed no significant effect of low number $(p=0.728)$, indicating no significant difference between low and high number conditions. Furthermore, there were no significant interaction effects between the dummy variables and empathy on motivation, $p>0.524$.

Overall, about $32 \%$ of all participants indicated serious helping intentions. Regressing helping intention on low number, high number, and empathy (Model 2), revealed that empathy, low number as well as high number significantly predicted helping intention. Thus, compared to control condition 
(about $42.2 \%$ ), significantly less participants intended to help in the high (26.2\%) and low (about 26.7\%) number conditions. These effects remained significant when additionally including need to belong, mindfulness, and global identity as further predictors. None of these variables significantly predicted helping intention; all $p s>0.082$. Again, including control condition instead of high number in the model revealed no significant effect of low number $(p=0.925)$, indicating no significant difference between low and high number conditions. There were no significant interaction effects between the dummy variables and empathy on intention, $p>0.532$.

\section{Discussion}

In the present study, we tested two opposing hypotheses regarding the effect of information about existing initiatives on willingness to help: According to a descriptive norm perspective [3], one would expect individuals to go with the flow, that is, to show an increased willingness to help when getting the information that others already do so. In contrast, according to a social loafing perspective [10], assuming that individuals expend less effort when working collectively than when working individually, such information would lead individuals to show a reduced willingness to invest effort in supporting refugees. The data of our experiment rather speaks against the descriptive norm perspective and supports the social loafing approach; willingness to help refugees was lower when information about existing initiatives was provided.

We further assumed the number of helping initiatives to moderate effects of normative influence and of social loafing. Compared to the no information control condition, participants reported lower willingness in the low number as well as in the high number condition. Contrary to our expectations, however, the number of existing initiatives did not make any difference. Beside the given possibility of low power, we suggest that the manipulation of the number of initiatives (low vs. high) did not affect participants' impression, which may be due to missing knowledge as a reliable anchor for establishing such an impression. Future research should assess certainty about such knowledge and also should try more extreme numbers instead of 25 and 170 initiatives. Furthermore, based on the present experiment, we cannot exclude the possibility that the differences rely on a pure "map effect". It could be, for example, that showing a map of their country primes people's national identity making them less positive toward refugees from abroad. To address this limitation, future experiments should include an additional control condition, showing just a map of Germany with no indication about helping initiatives.

Our results revealed dispositional empathic concern to be a strong predictor for willingness to help refugees. This is in line with previous research regarding empathy as a relevant factor for prosocial behavior [13]. Interestingly, given that we assessed willingness to help people from a different culture, one could conclude that empathic concern does not ask about in- or outgroups [14,15]. For understanding processes of social loafing vis-á-vis helping behavior, the ingroup versus outgroup distinction needs further empirical work. For example, Earley [21] showed that group performance was substantially decreased when people performed together with outgroup members (i.e., people from another nation) rather than ingroup members. Social support from fellow group members, however, could result in additional group motivation [22]. Thus, helping behavior on a societal level could also be affected by how strongly people identified with a "society that is helping refugees", or a specific subgroup (e.g., activists, regional).

The study was conducted at the beginning of December 2015. In the context of, for example, the picture of a drowned Syrian child at the beach (published before our conduction) or the sexual assaults in Cologne on New Year's Eve (i.e., after our conduction), we want to emphasize that overall willingness to help refugees is likely to be influenced by such information [23]. Interestingly, our effects of information about how many people are helping might depend on the occurrence of such events. For example, if willingness to help was increased to a high level through the above mentioned picture, a higher number of initiatives is probably needed to induce social loafing. On the other hand, assuming that this high level of willingness to help is driven by feelings of guilt [24], one might expect 
that already a low number of initiatives might offer people a way to reduce those feelings and further willingness to help. Based on this reasoning, future research should focus on the underlying processes and the conditions under which this kind of loafing versus normative social influence occur.

Nevertheless, the present finding is relevant both theoretically as well as for communication strategies. First, it appears that social loafing is not only a matter of performance and cognitive effort [10], but also extends to helping behavior. Second, these results show that social loafing might extend to whole societies, suggesting a process of societal loafing. We define societal loafing as the phenomenon of citizens exerting less effort to achieve social change when other citizens within a shared society already do so. In this vein, communication strategies that actually aim to motivate people via descriptive norms can sometimes lead to reduced motivation.

Acknowledgments: The authors thank Laura Bräuer, Rebekka Franz, and Jessica Kny for their assistance in data collection. The costs of publishing open access were covered by the University of Kassel.

Author Contributions: Simon Schindler and Gerhard Reese conceived and designed the experiments; Simon Schindler performed the experiment and analyzed the data; Simon Schindler and Gerhard Reese wrote the paper.

Conflicts of Interest: The authors declare no conflict of interest.

\section{References}

1. Hall, M.; Squires, N.; Holehouse, M. Migrant Crisis: Refugees Welcomed in Germany Like War Heroes as Berlin Expects 10,000 in One Day. The Telegraph. 6 September 2015. Available online: http:/ / www.telegraph.co.uk/news/worldnews/europe/germany/11847545/Migrant-crisis-Refugeeswelcomed-in-Germany-like-war-heroes-as-Berlin-expects-10000-in-one-day.html (accessed on 10 May 2017).

2. Integration von Flüchtlingen-Gute Ideen Bundesweit. Available online: https://www.tagesschau.de/ inland/hilfe-fuer-fluechtlinge-101.html (accessed on 11 May 2017).

3. Cialdini, R.B.; Kallgren, C.A.; Reno, R.R. A focus theory of normative conduct: A theoretical refinement and reevaluation of the role of norms in human behavior. Adv. Exp. Soc. 1991, 24, 201-234.

4. Cialdini, R.B.; Reno, R.R.; Kallgren, C.A. A focus theory of normative conduct: Recycling the concept of norms to reduce littering in public places. J. Pers. Soc. Psychol. 1990, 58, 1015-1026. [CrossRef]

5. Goldstein, N.J.; Cialdini, R.B. The spyglass self: A model of vicarious self-perception. J. Pers. Soc. Psychol. 2007, 92, 402-417. [CrossRef] [PubMed]

6. Nolan, J.M.; Schultz, P.W.; Cialdini, R.B.; Goldstein, N.J.; Griskevicius, V. Normative social influence is underdetected. Pers. Soc. Psychol. Bull. 2008, 34, 913-923. [CrossRef] [PubMed]

7. Goldstein, N.J.; Cialdini, R.B.; Griskevicius, V. A room with a viewpoint: Using social norms to motivate environmental conservation in hotels. J. Consum. Res. 2008, 35, 472-482. [CrossRef]

8. Reese, G.; Loew, K.; Steffgen, G. A towel less: Social Norms enhance pro-environmental behavior in hotels. Soc. Psychol. 2014, 150, 97-100. [CrossRef] [PubMed]

9. Ingham, A.G.; Levinger, G.; Graves, J.; Peckham, V. The Ringelmann effect: Studies of group size and group performance. J. Pers. Soc. Psychol. 1974, 10, 371-384. [CrossRef]

10. Karau, S.J.; Williams, K.D. Social loafing: A meta-analytic review and theoretical integration. J. Pers. Soc. Psychol. 1993, 65, 681-706. [CrossRef]

11. Shepperd, J.A. Productivity loss in performance groups: A motivation analysis. Psychol. Bull. 1993, 113, 67-81. [CrossRef]

12. Davis, M.H. Measuring individual differences in empathy: Evidence for a multidimensional approach. J. Pers. Soc. Psychol. 1983, 44, 113-126. [CrossRef]

13. Eisenberg, N.; Miller, P.A. The relation of empathy to prosocial and related behaviors. Psychol. Bull. 1987, 101, 91-119. [CrossRef] [PubMed]

14. McFarland, S.; Webb, M.; Brown, D. All humanity is my ingroup: A measure and studies of identification with all humanity. J. Pers. Soc. Psychol. 2012, 103, 830-853. [CrossRef] [PubMed]

15. Reese, G.; Proch, J.; Finn, C. Identification With All Humanity: The role of self-definition and self-investment. Eur. J. Soc. Psychol. 2015, 45, 426-440. [CrossRef] 
16. Pfattheicher, S.; Schindler, S. Misperceiving bullshit as profound is associated with favorable views of Cruz, Rubio, Trump and conservatism. PLoS ONE 2016, 11, e0153419. [CrossRef] [PubMed]

17. Cohen, J. Statistical Power Analysis for the Behavioral Sciences; Lawrence Erlbaum Associates: Hillsdale, NJ, USA, 1988.

18. Leary, M.R.; Kelly, K.M.; Cottrell, C.A.; Schreindorfer, L.S. Individual differences in the need to belong: Mapping the nomological network. Unpublished work. 2006.

19. Brown, K.W.; Ryan, R.M. The benefits of being present: Mindfulness and its role in psychological well-being. J. Pers. Soc. Psychol. 2003, 84, 822-848. [CrossRef] [PubMed]

20. Reese, G.; Kohlmann, F. Feeling global, acting ethically: Global identification and fairtrade consumption. Soc. Psychol. 2015, 155, 98-106. [CrossRef] [PubMed]

21. Earley, P.C. East meets west meets Mideast: Further explorations of collectivistic and individualistic work groups. Acad. Manag. J. 1993, 36, 319-348. [CrossRef]

22. Hüffmeier, J.; Wessolowski, K.; Randenborgh, A.; Bothin, J.; Schmid-Loertzer, N.; Hertel, G. Social support from fellow group members triggers additional effort in groups. Eur. J. Soc. Psychol. 2014, 44, 287-296. [CrossRef]

23. Scheufele, D.A. Examining differential gains from mass media and their implications for participatory behavior. Commun. Res. 2002, 29, 46-65. [CrossRef]

24. Renner, S.; Lindenmeier, J.; Tscheulin, D.K.; Drevs, F. Guilt appeals and prosocial behavior: An experimental analysis of the effects of anticipatory versus reactive guilt appeals on the effectiveness of blood donor appeals. J. Nonprofit Public Sect. Mark. 2013, 25, 237-255. [CrossRef]

(C) 2017 by the authors. Licensee MDPI, Basel, Switzerland. This article is an open access article distributed under the terms and conditions of the Creative Commons Attribution (CC BY) license (http:// creativecommons.org/licenses/by/4.0/). 